\title{
Estado y política fiscal en la crisis del Antiguo Régimen
}

\author{
LUIS LORENTE TOLEDO
}

El tránsito convulso o consensuado entre el Estado feudal y el Estado capitalista no tiene lugar en el momento en que aparece el Estado, una formulación que corresponde por otro lado a la consolidación de la dominación política de la clase burguesa, sino - tal como expresa N. Poulantzas 1_ en el momento en que aparece el Estado absolutista. Este Estado absolutista, precisamente bajo control borbónico, actuará en favor del modo de producción capitalista incluso, aunque este sistema de producción se encontrará aún lejos de ser dominante en la estructura económica del siglo XVIII y, en consecuencia, contribuirá con su función de acumulación primitiva, directa o indirectamente, a provocar nuevas relaciones sociales. La naturaleza del Estado, su función pues, estaría así «adelantada» o sencillamente desajustada en relación al campo de la economía y de las relaciones sociales existentes en el declinar de la estructura de antiguo régimen.

En el activo de esta tesis, como señala R. Robin ${ }^{2}$, se encontrarían las innumerables querellas entre la Monarquía y la Nobleza, pero en especial el pánico de ésta a las iniciativas fiscales y económicas de aquélla, desviando, en consecuencia, cualquier iniciativa del Estado en esta materia a una simple cuestión de subversión del orden social existente. En efecto, y de forma progresiva, el Estado de la Monarquía Absoluta venía dislocando profundamente al grupo señorial, debilitando, cuando no rompiendo, los lazos personales que eran su esencia, introduciendo en cada instante su justicia, sus leyes, su fisco, su ejército entre los nobles y sus hombres ${ }^{3}$. Un

Poulantzas, N., Pouvoir politique et classes sociales. París, Masperó, págs. 168-169.

Robin, R., "La naturaleza del Estado al final del Antiguo Régimen: Formación social, Estado y Transición", Dialectiques, ㄲo 1-2. París, 1962, págs. 31-53.

3 Mousnier, R., "Recherches sur les soulevements populaires avant la Fronde" en La plume, la faucille et le marteau... París, PUF, 1970, pág. 364. 
Estado que aunque nobiliario en su esencia, será autónomo con relación al estamento que le sustenta. No en vano quita progresivamente al cuerpo nobiliario del aparato del Estado en beneficio de la integración de la burguesía a la vez que ésta asume el previo y obligado proceso de feudalización y de incorporación al orden feudo absolutista vigente.

Del tenor de las tensiones monárquico-nobiliarias, dependerá precisamente la aceleración que la Monarquía dé a estas fuerzas de acumulación primitiva del capital. No podemos olvidar ni la connivencia interesada del Estado con la burguesía de Antiguo Régimen, como elemento disuasorio frente a la nobleza, ni la necesidad de la propia burguesía que no podía pasarse sin el Estado y su estructura para alcanzar sus fines. Pero tampoco en ningún caso se puede obviar la constitución subliminal del «frente de clases" entre clases explotadoras - burguesía y nobleza - contra las masas populares, esencialmente campesinas.

Este frente se sustentará precisamente en un Estado, cuya naturaleza invariable asume una función contradictoria puesto que es innovadora en cuanto posibilita un proceso de acumulación primitiva, al tiempo que conservado$\mathrm{ra}$, al ser garante de la reproducción de las relaciones señoriales. Sencillamente porque, como le definiera G. Durand, el Estado feudal-absolutista representa a la Nobleza y a la Burguesía, acelerando el desarrollo de las fuerzas productivas y garantizando la desigualdad del privilegio; pero no por ello se trata de un Estado por encima de las clases, sino que las mantiene en equilibrio reproduciendo las relaciones sociales del feudalismo. Así pues, Estado nobiliario sí, pero de forma compleja y con la importante contradicción de tener que precisar, a la vez que acelerar, el desarrollo de las fuerzas productivas y velar para que no se constituya una burguesía masiva, cuyo destino último podía no ser ya el mismo que el del Estado monárquico ${ }^{4}$.

En todo caso, esta esencial contradicción asumida por el Estado feudoabsolutista es resultante, sin duda, de su propia naturaleza invariable frente a la variable función de la burguesía que, dependiente del desarrollo económico e impulso marítimo comercial y paralelamente a su proceso de integración señorial, mantendrá su tendencia al crecimiento y al desarrollo del capital. En este sentido es muy aclaratoria la opinión de Cl. Mazauric sobre la complejidad de la naturaleza de la burguesía de Antiguo Régimen, pues al acumular el capital se convertía en acaparadora de renta de suelo, acreedora del propio Estado, beneficiaria de las colonias y, sobre todo, estaba deseosa de penetrar en el aparato del Estado mediante la adquisición de

4 Durand, G., État et Institutions, xvie-xvile siècles. Paris, U-Collection AC, 1980. 
oficios y en la nobleza por la compra de magistraturas o de cartas patentes; razón por la que durante mucho tiempo colaborará con la nobleza estrechamente bajo la égida del rey árbitro. En cuanto tal, esta burguesía se instala en el régimen feudal al mismo tiempo que lo mina. No tiende conscientemente a su destrucción en este estadio preliminar; la burguesía necesita del orden feudal para crecer desde el año 1750, porque la economía lo permite, y ya no querrá jugar sino el primer papel ${ }^{5}$.

Es un hecho, sin embargo, que las contradicciones entre burguesia y nobleza son -en el nivel económico - tan secundarias como lo serán entre este frente socio económico y el propio Estado. Hay más bien una convergencia de intereses desde el mismo momento que el propietario de la tierra necesita del desarrollo del capitalismo para asegurar el de sus rentas y los sectores capitalistas - usufructuadores del capital-, por su parte, necesitan aún de la propiedad de la tierra, por ser ésta la única que asegura el aprovisionamiento en mercancías agrícolas y, a medio plazo, la única que les asegura el aprovisionamiento de fuerza de trabajo para las manufacturas. B. Porchnev ya señaló para el caso francés, y el español no difiere en demasía durante la estructura dieciochesca, cómo en el transcurso del siglo XVIII la rápida evolución del capitalismo reforzó y desarrolló de tal forma la fracción no privilegiada de la burguesía que ésta se libró de la influencia de sus «hermanos mayores". Desde entonces, la institución de la venalidad de los cargos no respondía ya a su objeto inicial políticamente inútil, económicamente nociva, y fue, poco a poco, liquidada por la monarquía nobiliaria. La tendencia que predominará en la burguesía francesa del siglo xVIII debe ser, ciertamente, considerada como una de las dos tendencias antagónicas en el comportamiento de la misma durante el estadio inferior del capitalismo ${ }^{6}$.

El Estado del siglo xvIII, la estructura estatal de la llustración, inicia con estos parámetros un importante proceso de transición que, subsiguientemente, aboca al profundo y largo túnel de la crisis orgánica del sistema de Antiguo Régimen, es el mismo momento en que una fracción de la burguesía no podía estar o no quería mantenerse ya integrada en el orden feudal monárquico. R. Robin marca esta diferencia en el cuerpo burgués, denominando a un sector burgués stricto sensu por estar profundamente comprometido esencialmente en las relaciones de producción del capital y del dinamismo del mercado. $Y$ a una burguesía de «antiguo régimen» con base

\footnotetext{
5 Vid. Mazauric, CL., «Sur une nouvelle concepcion de la Révolution française», Annales Historiques de la Révolution Française, julio-septiembre. París (1967), pág. 93.

6 Porchnev, B., Les soulèvements populaires en France de 1623 a 1648. París, Sevpen, 1963, pág. 578.
} 
plebeya, oficial y terrateniente que, a finales de la centuria ilustrada en su conjunto, no quería continuar ya integrada en el orden feudal-absolutista, siendo ella misma quien iba a suministrar los intelectuales y profesionales liberales que le eran precisos?

Empero, esta crisis de identidad y de "qué lugar se ocupa o estado se tiene en la sociedad" irá mucho más allá del primario e instintivo cierre de los oficios ennoblecedores a la burguesía; estamos ante una crisis cuya profunda y subsiguiente transcendencia provocará el tránsito hacia el vuelco sociológico.

En efecto, el Estado absolutista para poder funcionar debió, por una parte, ir integrando masivamente y por urgente e imperativa necesidad dentro de su orden a una fracción esencial de la burguesía, precisamente con la intención de evitar su constitución como clase autónoma y, por ende, la producción de sistemas ideológicos corrosivos para la monarquía. Mientras, por otra, progresivamente irá dejando a la nobleza fuera del aparato estatal, para así finalmente poderse adaptar a la evolución de las fuerzas productivas; esto es, al nuevo y real ritmo que empezaba a marcar la fuerza del capital en su formulación de oferta y demanda por el mercado y a través del impulsivo y ascendente sector burgués.

Este Estado desde mediados del siglo XVIII entrará en consecuencia, por dinamismo social y económico, en crisis, en un desequilibrio perpetuo. No obstante, esta fenomenología estructural y orgánica no debe confundirse de ninguna manera con aquella otra que enmarca la crisis del momento final del antiguo régimen, esto es, con la crisis derivada de una coyuntura revolucionaria; porque sencillamente «la crisis revolucionaria corona en el marco de una coyuntura que le es propia, la crisis orgánica" ${ }^{8}$.

La crisis orgánica que L. Althusser ya definió sobre la base de las reflexiones de Gramsci, en efecto, es un período en el que la clase dominante puede perder su papel dirigente, su hegemonía ideológica, no por la destrucción sistemática de estructuras, instituciones y aparatos ni por la lucha minoritaria sino por la lucha de masas por la conquista de estos aparatos, para reemplazarlos por otros en el momento oportuno en función de la correlación de fuerzas, siempre que no se olvide que esta lucha por sí sola no basta ${ }^{9}$. Creemos importante añadir en este sentido, que las

7 Vid. RoBin, R., op. cit., pág. 47.

8 Furet, F., "Le catéchisme révolutionnaire", Annales de estudios económicos y sociales. París, marzo-abril, 1971.

9 Al.thUSSER, L., «idéologies et appareils idéologiques d' État», Le Pensée. París, junio, 1979. 
diferentes vías de transición pueden comportar mecanismos dispares y, en el caso español, el cambio desde la propia institución monárquica en pro de las fuerzas de acumulación es tan significativo para iniciar el cambio de la correlación de fuerzas, como pudo ser en el caso francés la lucha de masas. Es, pues, un inicio prematuro en España que tendrá su eclosión tardía en 1868, mientras el proceso estará salpicado de síntomas de desequilibrio: pronunciamientos militares, algaradas y conspiraciones sociales, todos ellos conatos revolucionarios más o menos fructíferos. De este modo la crisis orgánica se convierte por razón de las tentativas reales efectuadas por el Estado en reajustes, e intentos de reequilibrio en función de las transformaciones económicas, sociales, políticas e ideológicas que salpican el reinado de Carlos III en la España de la segunda mitad del siglo XVIII.

Enmárquense, en este sentido, la política de lucha contra los Parlamentos provinciales - fortalezas de privilegios y fueros privativos- a través de la abolición de las autonomías políticas con los Decretos de Nueva Planta - Valencia (1707), Aragón (1711), Mallorca (1715) y Cataluña (1716) - y el establecimiento de un modelo único de administración territorial. O la política en materia de fiscalidad centrada en tres ejes tendentes a suprimir el viejo sistema de percepción impositiva, implantando en su lugar un nuevo sistema basado en pocos impuestos, bien justificados y suficientemente productivos (Única Contribución), que se reunirian en un fondo común centralizado y administrado por el ministro de Hacienda.

Luego, la creación de organismos administrativos responderá más al deseo de acumulación de funciones, típico de la Monarquía absoluta, que a una concepción racionalista del Estado. Una política hacendística que, buscando el equilibrio impositivo con el reparto proporcional e igualitario en función de la evaluación de riqueza que se realice, tendrá como máximo opositor al estamento privilegiado. Precisamente su privativo "status", en última instancia objetivo principal de la reordenación fiscal, será el principal afectado por el sistema de aplicación tributaria directa sobre la base imponible evaluada por el Catastro.

La política económica dieciochesca será, igualmente, otro síntoma inconfundible del desequilibrio del Estado. Su política en favor de las nuevas doctrinas económicas - fisiocracia y liberalismo económico- en el marco del orden feudo-absolutista, confirmará el deseo económico de imbricar la filosofía del capital en la estructura existente y quedará muy patente en la mezcolanza de normativas existentes con la flexibilización de las reglamentaciones. Medidas tan importantes para la vida cotidiana y el comercio 
como la declaración de libertad de precios, con la consecuente abolición de la tasa y la libre circulación para el trigo (1765), o la progresiva implantación de la libertad de comercio con América para todos los puertos españoles, rescindiendo el sistema monopolístico mercantilista (1778), aparecerán junto a otras tan importantes para la propia libertad mercantil como la supresión de la limitación del control de las corporaciones, previa eliminación del sistema de control que los gremios ejercían sobre las técnicas y métodos de fabricación industrial. Una revolucionaria norma se manifiesta en el año 1790 al declararse la libertad para el ejercicio de cualquier oficio sin tener que pasar por el examen gremial. Las liberalizaciones comercial y productiva, sin embargo, tuvieron su obligada contrapartida en respuesta a la connivencia, al pacto suscrito por el Estado monárquico con el frente de clases explotadoras.

Así, por ejemplo, la liberalización del comercio con América no se aplicó al comercio exterior español en lo referente a productos industriales. Los gobiernos ilustrados mantuvieron también fuertes medidas proteccionistas a la importación de productos industriales. En el año 1760, por ejemplo, se decretó un recargo de un $25 \%$ en aduanas para las importaciones de tejidos de algodón. Una medida considerada insuficiente por los nuevos industriales que consiguieron que en el año 1769 se prohibieran las importaciones de tejidos de algodón y, en el año 1775, la importación de productos de ferretería.

La mayor concienciación del Estado monárquico absoluto, no obstante, estará en la problemática agraria y en el diseño de una adecuada política económica en este sector. $Y$ en gran medida por la aparición de Intendentes reformadores en las provincias — «Intendentes ilustrados»-que tomarán la defensa de las comunidades campesinas.

Hasta el punto de que la personal asunción de las protestas en torno a los arrendamientos agrarios, a las roturaciones de tierras incultas, a las disputas con los ganaderos, a la falta de tierras para cultivar y, por tanto, para sobrevivir, e incluso su abierta defensa, situarán a los «representantes ministeriales» frente a la oligarquía local. Una problemática que se unía a la existente, en consecuencia, en las zonas urbanas dadas las serias dificultades de abastecimiento de trigo y el elevado precio del mismo. Y su eclosión fue en el año 1766, año en el que, tras ser decretada la liberación de precios del trigo el año anterior, la cosecha resultó insuficiente y el precio del trigo se disparó de forma alarmante, estimulando definitivamente al Estado a plantearse la problemática de la agricultura española.

Aquel movimiento tuvo un tratamiento teórico manifiesto en el «Expediente General» formado por el Consejo de Castilla. Su claro objetivo 
era la conformación de una ley agraria, para lo cual era preciso contar con un conjunto de documentos preparatorios elaborados por equipos ilustrados entre los años 1770 y 1794. Esta ley, que fue non nata, sin embargo dio lugar a un conjunto de Informes de los que derivaban posibles e importantes soluciones desde la óptica concreta de cada una de las regiones agrarias. La «Respuesta del fiscal en el Expediente de la provincia de Extremadura" de Floridablanca (1770), el "Memorial ajustado" de Campomanes (1771) y el «Informe de la Ley Agraria» de Jovellanos (1794), constituyen un conjunto de informes ilustrados que permitieron adoptar a los gobiernos ilustrados algunas medidas muy significativas de lo que hubiera podido ser la Ley Agraria a la que éstos se encaminaban.

La política de repoblación iniciada en 1749 por Ensenada y continuada con empuje por Carlos III, especialmente con el experimento dirigido por el intendente de Andalucía - Olavide - en Sierra Morena; la política de supresión de los privilegios de la Mesta iniciada en 1758 y, en especial, a partir de los decretos de 1779-1788 que autorizaban a los propietarios de fincas a los cercamientos 10; o la política sobre las tierras de propios, a partir de la medida del Intendente de Badajoz, que se encaminaba a repartir en arrendamiento las tierras de propios entre el vecindario más pobre de cada municipio. Una medida extensiva a partir de 1766 a toda Extremadura, y más tarde a todo el país, cuyo tenor era proporcionar a los campesinos más pobres, como el caso de los yunteros poseedores de medios de producción como la yunta de bueyes pero no del factor generativo, tierras en condiciones de arrendamiento más favorables a las existentes en el sistema contractual habitual.

Por su parte, la oligarquía municipal encargada de poner en práctica la medida, se encargó de desvirtuar su aplicación al convertirse, en la mayor parte de los casos, en beneficiaria de estos arrendamientos. Junto a esta medida se sitúan otras dos. La primera sobre arrendamientos agrarios que, pretendiendo normalizar el sistema productivo, congelaba los precios de los arrendamientos de tierras desde el año 1785 y fijaba a los poseedores del dominio útil al factor tierra. Hasta que Carlos IV, que ratificó la ley en el año 1794, la derogó en el subsiguiente de 1803. La segunda tendente a ampliar la superficie productiva con los primeros intentos de desamortización de tierras de manos muertas, encaminados a poner en venta desde 1798 las propiedades de obras benéficas administradas por el

10 Sobre la política general de las autorizaciones de cercamientos y establecimiento de estructuras capitalistas en el ámbito agrario, LEON, P., "La montée des structures capitalistes", en Histoire économique et sociale de la France. París, PUF, t-II, pág. 161 a 321. 
clero (una sexta parte de las propiedades eclesiásticas en la Corona de Castilla). La venta fue llevada por el gobierno y los fondos obtenidos se destinaron a salvar las dificultades del Erario público; a cambio se estableció un fondo que sufragaría las necesidades de las instituciones que habían perdido sus propiedades.

Todo un conjunto de reformas que apuntaban inconscientemente a un compromiso social entre la nobleza y la burguesía, a un paso del liberalismo económico «desde arriba» a la manera del despotismo ilustrado. Que este compromiso fracasara -como señala A. Pelletier ${ }^{11}$ para el caso francés- no significa que fuera imposible, cuando en España fue evidente en todo el período de la transición al liberalismo.

Un compromiso entre fuerzas sociales sí, pero, sin duda, bajo la tutela del Estado; porque es peligroso considerar al Estado como un simple apéndice de la clase dominante aristocrática, sobre todo, en períodos de transición y, por consiguiente, de desajustes entre las instancias de la formación social. El Estado tiene una forma de intervención propia, una eficacia específica:

«(...) la repercusión del poder del Estado sobre el desarrollo económico puede revestir tres formas. Puede obrar en el mismo sentido y entonces todo marcha más deprisa; puede actuar en sentido inverso al desarrollo económico y en nuestros días esta forma ha fracasado en todos los grandes pueblos al cabo de un tiempo determinado; o bien puede cerrar al desarroIlo económico unas determinadas vías y prescribirle otras, y en este caso acaba por remitir finalmente a uno de los dos precedentes. Pero está claro que, en el segundo y tercer caso, el poder político puede causar un grave quebranto al desarrollo económico y producir un gasto masivo de fuerza y materia» 12 .

El Estado, pues, no es ni debe plantearse como un simple fenómeno de la clase dominante. Su intervención puede ir perfectamente contra los

11 Pelletier, A., ha señalado en «A. Soboul et la Révolution Française», publicado en $L a$ Pensée, n 163, París, junio de 1972, pág. 126, que «...la clase feudal misma podia, a priori, considerar evitar una revolución, las condiciones de su adaptación al capitalismo moderno, de su asociación a la clase burguesa; de esta adaptación, la Inglaterra de 1688 había proporcionado ya una versión y existían otras sobre todo la prusiana: la teoría marxista nos propone la posibilidad de estas dos vias que la $\mathrm{H}^{\mathrm{a}}$ moderna y contemporánea ilustran ampliamente y no hace, de ningún modo, a priori, de la vía francesa una vía necesaria para Francia (...), hacia 1760-1770 nuestra monarquía (la francesa) intentó esta adaptación y chocó con una oposición no menos fuerte que fáctica no sólo de la nobleza sino de la burguesía, entonces y en este caso aliada (...); para romper esta alianza, Luis xv hubiera debido, cuando menos, conceder la igualdad civil y fiscal".

12 ENGELS, F., «Carta de Conrad Schmidt», 27 de octubre de 1890. 
intereses bien comprendidos de la clase privilegiada, al faltar la adaptación necesaria para la evolución de las fuerzas productivas, y viceversa. Su inclinación social dependerá precisamente del desarrollo y evolución del capitalismo en las primeras etapas. El mismo ascenso y dominio del capital irá, en consecuencia, adaptando para sí las formas de posesión de la tierra y de la economía del sistema feudal en el que se inserta; hasta hacer posible el denominado feudalismo desarrollado; aquél en el que el propio modo de producción feudal remanente entraña la extorsión del trabajo excedente y/o del plusproducto a través de una coerción extraeconómica añadida e impuesta por el mismo capital.

Se establecía así un régimen híbrido, denominable señorial en cuanto el antiguo señor feudal sufría el acoso del dinamismo del capital. $Y$, en consecuencia, el feudalismo de antiguo régimen característico de sociedades agrícolas de evolución técnica lenta y de intercambios limitados, en las que el plusproducto del trabajo de la mayoría de la población constituida por pequeños productores aparecía acaparado, mediante una coerción extraeconómica, en beneficio de una minoría definida jurídicamente ${ }^{13}$.

La disolución de las antiguas relaciones de propiedad estará ligada al desarrollo de la riqueza monetaria, del comercio — variables determinantes de la burguesía-, que al penetrar en el sistema feudal van a crear un estadio primitivo de acumulación a partir del cual el capitalismo tenderá a la constitución, en el seno de una sociedad de reminiscencias feudo-vasalláticas, de una clase de poseedores de capital que precisarán de una masa de individuos libres y de un mercado interior. Tendencias que, antes de provocar la ruptura de sistemas, harán posible la integración y, sin menoscabo del equilibrio, la incorporación progresiva de estos desarrollos cualitativos nuevos al viejo orden:

«(...) El sistema capitalista de producción en sus comienzos se encuentra en presencia de una forma de propiedad de la tierra que no le corresponde. Él, solamente, crea la forma que le conviene subordinando la agricultura al capital; por ello, también, la propiedad feudal de la tierra, la propiedad de clanes, la pequeña propiedad campesina con comunidad de mercado, se ha metamorfoseado en la forma económica correspondiente a este modo de producción por diversas que sean sus formas jurídicas» ${ }^{14}$.

Por su parte, las supervivencias del feudalismo adaptarán por sí mismas las relaciones burguesas y «barbarizarán» el desarrollo social del

13 VILAR, P., Cataluña en la España Moderna. Barcelona, 1978.

14 Marx, K.: El Capital. México, 1973. Libro III, tomo VIII, pág. 9. 
país. En suma, se entra en una dinámica de transición, cuando en la formación social el sistema productivo que regula las relaciones superestructurales, en particular jurídicas, no es ya dominante, sin que aún sea dominante el modo productivo que disuelve y descompone el antiguo. De todo ello, además de las transformaciones en el interior de los señoríos y el cambio experimentado en las relaciones sociales en el campo ${ }^{15}$, es prueba fehaciente la ascensión de la burguesía rural emprendedora ${ }^{16}$.

A estos cambios cualitativos que, aun considerados en su entorno feudal son demasiado concomitantes para no constituir un conjunto corrosivo y dislocador del modo de producción existente, se une el deseo de reformar la Hacienda, en gran medida por la presión de las fuerzas de acumulación y las necesidades crecientes del propio Estado. La burguesía para poder producir para el mercado, acumular «stock» y especular según las leyes de mercado, necesitará el equilibrio en la presión fiscal, la libertad comercial y, por supuesto, la modificación del estatuto y sistema de propiedad y explotación de la tierra. El Estado, por su parte, necesitará más ingresos sólo posibles previa racionalización y unificación del dispar sistema de percepción impositiva.

Únicamente con un Erario saneado y eficaz podría acelerarse la intervención de las fuerzas que transformasen el interior de los señoríos y las relaciones sociales en él existente; y ello porque el mismo sistema impositivo podría mermar los lazos de poder y de posesión de la estructura señorial en el mismo momento que atacara al "status" privilegiado en materia fiscal.

Efectivamente, una reforma a fondo del sistema impositivo - como la planteada por los Borbones en el s. XVIII- implicó siempre la posibilidad de efectuar una redistribución de rentas entre sus habitantes. Motivo por el que en torno a la reforma fiscal proyectada en el año 1736 e iniciada en el de 1749 por Ensenada con la evaluación catastral de la riqueza en la Corona de Castilla(1750) ${ }^{17}$ y concluida con el sistema Mon del año 1845 hubo fuertes tensiones políticas ${ }^{18}$; las propias, por otro lado, de un Estado en crisis orgánica en proceso de transición hacia la implantación del sis-

15 Como señala MOUSNIER, R. y HARTUNG, F., «Quelques problèmes concernants la monarchie absolue», X Congreso Internacional de Ciencias Históricas. Roma, 1955, Relazioni, 4.

16 Según ha señalado PARAIN, CH., «La differentiation sociale à interieur de la communauté villageoise", en L'Aubrac ethnologie historique, transhumance ovine. París, CNRS, 1971, tomo II, pág. 88.

17 DonÉzAR, J., Riqueza y Propiedad en la Castilla del Antiguo Régimen. Madrid, M.A.P.A., 1984.

18 LORENTE, L., La Reforma fiscal del último tercio del siglo xvII en Toledo. Toledo, 1985. 
tema liberal. Es por ello que no fue por casualidad que la quiebra de la Hacienda del Antiguo Régimen ${ }^{19}$ fuera paralela a los primeros síntomas de inestabilidad de la Monarquía absoluta.

Carlos III tras intentar desenterrar el proyecto Ensenada, cuya primera fase sobre evaluación catastral de la riqueza ya se había realizado y plasmado en 1750 con la confección del Catastro, puso en marcha una nueva etapa consistente en el reparto provincial de las cantidades a recaudar por el gobierno. Tal fue el número de recursos por la forma concreta de aplicación y reparto de las cantidades y la resistencia del estamento privilegiado que el proyecto de reforma fiscal tuvo que ser abandonado definitivamente en 1776. Demostrándose así, una vez más, incluso en el nivel económico-fiscal, la necesidad de la coyuntura revolucionaria para la eclosión de la crisis orgánica.

La inexistencia de aquella efervescencia de cambio que suponía cualquier proceso revolucionario o alteración del orden existente, y la imposibilidad de adoptar una vía de compromiso entre las fuerzas sociales privilegiadas y el Estado monárquico, marcó una larga transición y agonía para el acontecer del sistema de antiguo régimen español. Su plasmación en el vaivén de aplicación de proyectos fiscales es significativa, por cuanto refleja cómo la ruptura es sustituida por la quiebra lenta a través de la implantación de sistemas impositivos, cuyo tenor feudo-aristocrático o burgués-capitalista obedeció al triunfo de determinados pronunciamientos de corte liberal, a situaciones bélicas 0 , sencillamente, a la necesidad de apoyarse en una fracción política determinada ante una coyuntura dinástica.

Un rápido repaso por el suceder de la Hacienda del Antiguo Régimen, tras perder la primera oportunidad de aplicar una reforma fiscal que aunara la politica de Estado y los recursos necesarios para su mantenimiento con una «Única Contribución», nos manifiesta cómo no queda más alternativa en el débil y estrecho aparato del sistema que sostener el antiguo sistema de «Rentas»; eso sí, con un simple retoque de las tasas impositivas de las «rentas provinciales y equivalentes» por la necesidad de recursos extraordinarios ante la guerra con Inglaterra. Sólo podemos considerar como intentos que apuntan hacia la reforma fiscal, la iniciativa de Floridablanca de una «Contribución de frutos civiles» - un nuevo deseo de plasmar el viejo plan de contribución sobre la renta-, o la revisión de los «encabezamientos provinciales» en cuanto a volumen de sus contribuciones

19 Artola, M., La Hacienda del Antiguo Régimen. Madrid, Alianza Editorial, 1974, cap. V: «La quiebra de la Hacienda del Antiguo Régimen 1779-1808», pág. 321-459. 
para promover, en la medida de los recursos, el desarrollo natural de cada provincia mediante la constitución de fondos de socorro destinados a promover la agricultura y la industria.

La necesidad de recursos extraordinarios para el mantenimiento de la situación bélica con Inglaterra (1779-83 y 1793-1801), además del incremento en las rentas provinciales, supuso acudir a medidas y recursos extraordinarios como la aplicación del sobrante de Propios y Arbitrios para el pago del tercio aumentado en las rentas provinciales; o la aplicación de censos consignativos sobre los caudales de estas rentas que se tomarían de los estamentos privilegiados ${ }^{20} ; \mathrm{y}$, por supuesto, abrir nuevas fuentes de financión como el intento de cobrar en América sobre la población libre y la aplicación de las primera medidas desamortizadoras sobre bienes de obras pías y beneficiencia, capellanías, según el Breve de 12 de diciembre del año 1806, y las vinculaciones de mayorazgos de acuerdo con el Real Decreto de 11 de enero del año 1799.

El exhausto estado del erario público eclosionó en 1808 junto a los motines populares en respuesta a la situación nacional. La Junta Central no teniendo ni la más mínima posibilidad pecuniaria tuvo que poner en marcha una extraordinaria y urgente "Contribución de guerra» durante los años 1808-1811 por un montante de seis millones y medio de reales, entre otras razones para poder sostener la guerra contra el invasor.

Sin embargo, el deplorable resultado recaudatorio no evidenciaba más que la indigencia de la mayoría y la resistencia de los sectores privilegiados, cuyo «status», aunque les seguía eximiendo de aparecer en los amillaramientos, no les aislaba del movimiento de capitalización de las rentas del suelo. Además, la estructura precapitalista del arrendamiento hará posible que el señor obtenga sus rentas infinitamente más que de los derechos feudales, entrando en una dinámica hacia la conversión en propietarios terratenientes sin mayores obligaciones que las eximentes contempladas para el factor generativo tierra, precisamente porque el sistema fiscal se fundamentaba en la tributación indirecta y, sólo en casos extraordinarios, en la directa de repartimiento entre los mayores contribuyentes de aquélla.

La división política del Estado a causa del expansionismo napoleónico bifurcó el sistema fiscal,creando un doble sistema impositivo de acuerdo con las dos realidades o dominios políticos establecidos en el bienio 1812-

20 Lorente, L., Privilegios, Rentas y Derechos de Toledo en el Antiguo Régimen 1760-1833. Toledo, 1989. 
1814. El sistema «francés» del entronizado José I, aunque con los caracteres propios del freno revolucionario que supuso el Imperio en el proceso francés, se centró en la imposición directa o "Contribución en granos y en especies" para el aprovisionamiento in situ del ejército conquistador que, al igual que en los mejores momentos de la Francia revolucionaria, tuvo que llevarse a efectos mediante la requisa militar. El sistema como tal era eficaz, pues no exigía en principio algo tan imposible para las circunstancias del momento como era el numerario, por no existir simplemente la circulación real del mismo en la situación concreta de un ya largo período de ocupacion. El alargamiento de esta supuesta coyuntura de ocupación hizo, sin embargo, a corto plazo tan imposible exigir la escasa renta/dinero como solicitar la vital y necesaria renta/especie, ante los indudables síntomas de precariedad y deterioro creados por el vaivén de las tropas en la base de subsistencia.

El fracaso en la aplicación de los cupos en especies llevará al gobierno francés a no retrasar más la imprescindible solicitud contributiva en numerario. Con este fin formulará la denominada «Contribución rural» sobre el patrimonio rústico, al tiempo que aplicará el mecanismo desamortizador principalmente sobre los patrimonios eclesiásticos abandonados y de órdenes suprimidas, aunque siempre con muy escasos resultados tributarios dada la cortedad temporal de aplicación de la propia normativa fiscal y la resistencia popular e institucional hacia su desarrollo.

La resistencia española, por su parte, se plantea, desde el reducto gaditano donde asume la soberanía nacional el 24 de septiembre de 1810 con la fórmula de las Cortes, el establecimiento de un sistema tributario que recogiera los avances y la aceleración dada por la monarquía absoluta en la centuria anterior. En este sentido y tras complicados debates, la burguesía del Antiguo Régimen empezó a desmarcarse del orden feudoabsolutista, proporcionando a la escasa burguesía stricto sensu mecanismos para afianzar las relaciones de producción capitalistas; así salió a la luz un sistema único de imposición directa muy al unísono con el proyecto Ensenada de Única Contribución y al igual que aquél no llegaría a aplicarse.

La restauración de Fernando VII inclinó la balanza fiscal al sector privilegiado, devolviéndole la inmunidad con el establecimiento del ancestral sistema de rentas. No obstante, el cambio operado durante los años precedentes en las relaciones sociales dentro del contexto rural vino a hacer posible un importante cambio cualitativo en el campesinado, ante la aparición de una burguesía rural escasa pero emprendedora, y sobre todo útil. En efecto, este heterogéneo nuevo sector socio-económico supo 
aprovechar en gran medida y muy bien los recursos desamortizados que introducía el trabajo asalariado e iniciar con ellos, también porque las circunstancias políticas de ascensión del liberalismo lo permitían, un proceso de acaparación de superficie productiva de cara al mercado; allí donde había verdaderamente ya una necesidad de vender la fuerza de trabajo para subsistir por la marcada aceleración que recibian las relaciones de mercado. Entre otros muchos factores, estaba motivada por la depauperización del medio social rural y la consecuente indigencia galopante de los contribuyentes "controlados", en su mayoría pequeños productores; ya que el proceso en sí obligaría al Estado a acelerar el proceso de acumulación en detrimento del sector privilegiado y haría factible en medio del sexenio absolutista un conato de reforma fiscal en la figura de Martín de Garay; quien quiso presentar la novedad del viejo proyecto de “Contribución única» en el año 1817.

Las tensiones que suscitaron la tributación directa sobre el patrimonio, nunca bien evaluado ante las eximentes y las ocultaciones, provocaron dos años de inestabilidad fiscal que sirvieron, en gran medida, si no al triunfo, por lo menos a la pasividad ante el pronunciamiento de Riego en $1820{ }^{21}$. Entre otras razones porque la situación financiera interior era lo suficientemente deplorable para desviar fondos que sostuvieran a un ejército encargado de acallar los deseos emancipadores americanos.

El triunfo liberal fue bien acogido tanto en los ámbitos urbanos, por lo que suponía para la implantación del propio sistema de producción capitalista, como en los rurales, donde el cambio cualitativo del campesinado le permitió identificar al liberalismo con la «liberación de cargas de origen feudal» ${ }^{22}$. Lo cual supuso, sin duda, retomar uno de los importantes debates gaditanos sobre los derechos jurisdiccionales y solariegos. Sin embargo, en materia fiscal, el doctrinarismo del liberalismo restableció el proyecto doceañista de sistema impositivo directo e igualitario, admitiendo el sentir del progresismo liberal con la implantación de los «años económicos" y el plan hacendistico de 1821. Los ejes principales de este plan quedaban articulados en una imposición directa que gravase el patrimonio —Contribución directa de 180 millones de reales sobre bienes rústicos y predios urbanos»- y la industria y el comercio — «Contribución directa

21 LoRENTE, L., Hacienda local y política económica en la España de Fernando vil. La provincia de Toledo 1814-1833. Toledo, Universidad de Castilla-La Mancha, 1990.

22 Ibidem. «Reforma agraria y señoría urbano en el liberalismo decimonónico. El movimiento campesino de los Montes de Toledo", Studia Historia, $\mathrm{n}^{\mathbf{a}}$ monográfico Estudios sobre el liberalismo, vol. VIII, Universidad de Salamanca, 1990. 
sobre patentes industriales y comerciales"-. El frente de "clases explotadoras" se vio así directamente afectado, pero también de manera indirecta, al establecerse paralelamente una "Contribución indirecta de 100 millones sobre consumos».

Este cuadro fiscal se ampliaba con una nueva medida desamortizadora sobre el patrimonio eclesial, tras aplicar una nueva ordenación que llevaba a la supresión de las órdenes eclesiásticas regulares que no tuvieran un fin social, cuando el principio atemporal de las mismas y no utilitarista era conditio sine qua non de sus fundaciones, se cumpliera o no a posteriori. Una manera encubierta por parte del propio Estado, sin duda, de comprometerse con el desarrollo de las relaciones capitalistas, asumiendo el cambio de las relaciones sociales, al tiempo que se facilitaba la puesta en marcha del proceso de acumulación primitiva especialmente sobre un vasto patrimonio hasta el momento no disponible e inmune a las presiones del capital, cual era el eclesiástico regular.

El vaivén político y, de nuevo, la unión de la oligarquía imposibilitaba el éxito de la reforma fiscal. Sus dos años de aplicación fueron escasos para ofrecer resultados. Por ello, el relevo político consciente de los problemas de tiempo y no de método no dio un giro total a la politica fiscal, buscó el consenso entre la tradición y la modernidad en el sistema López Ballesteros; se rescataron viejas contribuciones - de "frutos civiles" y de «paja y utensilios»- sobre la producción para crear un sistema consensuado que, sin embargo, a duras penas permitieron afrontar la circunstancia extraordinaria de la primera guerra civil española por cuestión dinástica.

El recurso extraordinario, en este caso doble, quedaba nuevamente explícito desde 1837 dadas las urgentes y perentorias condiciones del Erario Público. Tanto con la «Contribución extraordinaria de guerra de 600 millones de reales", como con la "Desamortización de los bienes del clero regular», el objetivo de Mendizábal era claro: sostener el proceso bélico contra el carlismo para así afianzar el trono y con él la opción del liberalismo. Política y fiscalidad tenían, de nuevo, un sentir y una finalidad común, tal como heredara de la proyección ilustrada del Estado. La insuficiencia de la recaudación, no obstante, obligó a Espartero a admitir la extensión de los recursos extraordinarios hasta el año 1844 con el establecimiento de 180 millones para la "Contribución de guerra» y la "desamortización del clero secular»; aunque esta última aplicación desamortizadora contemplara ahora la novedosa contrapartida de una contribución para sostener el «culto y clero», sustitutoria de los recursos ordinarios que el estado eclesial obtenía del patrimonio y de las rentas que ahora se nacionalizaban y que se fijaba a modo de 
salario que la empresa - el Estado- daba por el trabajo, servicio y fin social prestado - la asistencia espiritual y el sostenimiento del culto-, tal como imperaba y se pretendía establecer con las leyes de mercado en las relaciones productivas de mediados de la centuria decimonónica.

El sistema Mon del año 1845 vendrá a consolidar el sistema fiscal con el "Subsidio de industria y comercio", la «imposición sobre inmuebles, cultivos y ganadería» y la «imposición sobre consumo público», reiteración contributiva de aquella señalada en el Trienio que se estabilizará al igual que el modelo politico del liberalismo. Un sistema que no podía carecer, por suspuesto, del recurso extraordinario que permitiera sanear el lastre heredado en materia de fiscalidad principalmente desde la formación del Estado absoluto, y por esta razón se perfiló el último intento de sanear el déficit con recursos exógenos que al mismo tiempo permitieran consolidar a la clase ascendente - la burguesía - al acceder a bienes patrimoniales que mas que un beneficio económico directo, reportarían consideraciones sociales y preeminencias de antiguo status como las adyacentes al factor fijo tierra. La desamortización general de 1855, aunque destinada principalmente a acabar con las últimas reminiscencias del régimen señorial, esto es los bienes de propios y comunales de los municipios, su carácter de «general» permitirá la misión de aliviar al Estado de las supervivencias señoriales del estado eclesial, al mismo tiempo que le reportará beneficios, aunque exiguos, de su venta y transacción a los sectores oligárquicos, con los que cumplía la obligación de agradecerles el tránsito al Estado liberal.

A partir de este momento, la reforma fiscal estaba aplicada y el Estado además con la modificación del estatuto de la propiedad agraria eclesial, nobiliaria y municipal había dislocado profundamente al gran grupo señorial y preeminente, le habia debilitado en sus lazos personales que era la esencia de su vinculación, en sus preeminencias fundamentadas en la privativa posesión de la tierra y le había aplicado además su fisco en detrimento del secular privilegio de exención. Había acelerado, en contrapartida, a las fuerzas de acumulación de tal manera que la burguesía se había negado a seguir siendo ya de segunda fila y aún menos espejismo de las clases privilegiadas. Era el momento propicio para un cambio en la correlación de fuerzas; el pacto del frente de clases se tambaleaba y los «apoderados» deseaban ser iguales a los "señores absentistas», no obstante el desequilibrio del proceso de transición iba a requerir aún la aparición de la crisis revolucionaria.

Razón por la cual, la lenta y progresiva agonia de la estructura del Antiguo Régimen durante la consolidación del liberalismo en el poder se dilatará hasta hallar su eclosión en el año 1868. Entonces la quiebra del sistema feudo-absolutista estalló teóricamente, aunque en la praxis la 
agonía del viejo régimen tuvo tiempo suficiente para imbricarse primero con el ascendente y alternativo aparato del capital, y así después quedar absorbido por el propio dinamismo de la economía de mercado. Aquella que a través de la burguesía y sus círculos de élite oligárquica supo lentamente y sin convulsión en el caso español, más bien con la singular cohabitación en un frente de clases, metamorfosear a través de una pactada y consensuada asimilación las preeminencias señoriales y convertirlas en novedosas rentas del capital.

Cuando el proceso de consolidación del liberalismo estuviera cumplido y el pacto oligárquico sobreseído por la identificación total en un único y monolítico frente entre los «estamentos» aristocráticos procedentes del viejo sistema y la nueva élite del tercer estado, será entonces el momento de coronar todo el proceso social, económico y político con la crisis de conyuntura. Algo por lo demás de obligado cumplimiento en el devenir histórico del proceso y necesario por supuesto para sellar y consolidar el ascenso burgués, como propio y consustancial al mismo proceso de crisis orgánica a la que llegó la estructura del Estado del Antiguo Régimen. 